\title{
In Silico Study of Full-Length Amyloid $\beta$ 1-42 Tri- and Penta-Oligomers in Solution
}

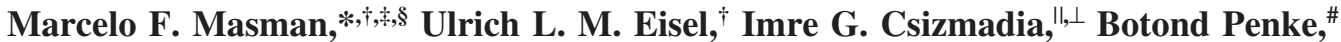 \\ Ricardo D. Enriz, ${ }^{\S}$ Siewert Jan Marrink, ${ }^{\dagger}$ and Paul G. M. Luiten ${ }^{\dagger}$ \\ Department of Molecular Neurobiology, University of Groningen, Kerklaan 30, 9751 NN Haren, The Netherlands, \\ Department of Biophysical Chemistry, University of Groningen, Nijenborgh 4, 9747 AG Groningen, The Netherlands, \\ Departamento de Química, Universidad Nacional de San Luis, Chacabuco 917, San Luis, Argentina 5700, \\ Department of Medical Chemistry, University of Szeged, Dóm tér 8, H-6720, Szeged, Hungary, Department of \\ Chemistry and Chemical Informatics, University of Szeged, Boldogasszony sgt. 6, H-6725, Szeged, Hungary, \\ and Department of Chemistry, University of Toronto, 80 St George Street, Toronto, Ontario, Canada M5S $3 H 6$
}

Received: February 5, 2009; Revised Manuscript Received: June 23, 2009

\begin{abstract}
Amyloid oligomers are considered to play causal roles in the pathogenesis of amyloid-related degenerative diseases including Alzheimer's disease. Using MD simulation techniques, we explored the contributions of the different structural elements of trimeric and pentameric full-length $\mathrm{A} \beta_{1-42}$ aggregates in solution to their stability and conformational dynamics. We found that our models are stable at a temperature of $310 \mathrm{~K}$, and converge toward an interdigitated side-chain packing for intermolecular contacts within the two $\beta$-sheet regions of the aggregates: $\beta_{1}$ (residues 18-26) and $\beta_{2}$ (residues 31-42). MD simulations reveal that the $\beta$-strand twist is a characteristic element of $\mathrm{A} \beta$-aggregates, permitting a compact, interdigitated packing of side chains from neighboring $\beta$-sheets. The $\beta_{2}$ portion formed a tightly organized $\beta$-helix, whereas the $\beta_{1}$ portion did not show such a firm structural organization, although it maintained its $\beta$-sheet conformation. Our simulations indicate that the hydrophobic core comprising the $\beta_{2}$ portion of the aggregate is a crucial stabilizing element in the $\mathrm{A} \beta$ aggregation process. On the basis of these structure-stability findings, the $\beta_{2}$ portion emerges as an optimal target for further antiamyloid drug design.
\end{abstract}

\section{Introduction}

Proteins can adopt an amazing array of sequence-dependent structures that enable them to perform the myriad of chemical functions critical to life. However, over the past decade, it has become clear that many different proteins can also form misfolded structures leading to insoluble aggregates. With respect to human brain functioning, protein misfolding can have dramatic consequences and can result in devastating diseases of the brain. There are several known degenerative diseases whose pathogenic mechanism is based on the pathological aggregation of polypeptides. These types of neurodegenerative diseases include Alzheimer's disease (AD), Parkinson's disease, Huntington's disease, prion diseases like Creutzfeldt-Jacob disease, and type II diabetes. ${ }^{1-3}$ It is a common feature to all of the above-mentioned diseases that the native structure of the specific peptides has been changed and that, during a fast aggregation process, they provide fibrillary products which are toxic to nerve cells or nervous tissue and resistant against enzymatic breakdown. The most extensively studied amyloidassociated disease is $\mathrm{AD}$, which is characterized pathologically by abnormally high numbers of amyloid or senile plaques in the cerebral cortex and amyloid deposits in the walls of cerebral blood vessels, and by neurofibrillary tangles in dead and dying neurons. ${ }^{4}$ Amyloid plaques are brain lesions that are composed

* Corresponding author. E-mail: M.F.Masman@rug.nl. Phone: +31 50 363 2337. Fax: +31503632331.

Department of Molecular Neurobiology, University of Groningen.

* Department of Biophysical Chemistry, University of Groningen.

$\S$ Universidad Nacional de San Luis.

"Department of Chemistry and Chemical Informatics, University of Szeged.

$\perp$ University of Toronto.

${ }^{\#}$ Department of Medical Chemistry, University of Szeged. of amyloid polymers and degenerating neurites accompanied by activated microglia, the inflammatory cells of the brain. The major component of amyloid plaques is a small peptide of $39-43$ amino acids in length called $\beta$-amyloid $(\mathrm{A} \beta)$, which is a proteolytic splicing product of the large amyloid precursor protein (APP). Compelling evidence now indicates that factors which increase the production of amyloidogenic variants of $\mathrm{A} \beta$, or which facilitate deposition or inhibit elimination of amyloid deposits, are major risk factors for AD. ${ }^{5}$

Currently, more than 20 different forms of $\mathrm{A} \beta$ are known, ${ }^{6}$ some of which are rare and some of which play central roles in the pathogenesis of diseases affecting millions of patients worldwide. The investigation of amyloid, as a major example of pathology due to protein misfolding, has become a widely studied enterprise. ${ }^{7-13}$ Consequently, the $3 \mathrm{D}$ structure of the amyloid polymers and fibrils is a focus of interest both for a molecular understanding of amyloidogenesis and for the development of innovative therapeutic and diagnostic approaches. Solid-state NMR studies have contributed substantially to the understanding of amyloid fibrils. ${ }^{14,15}$ However, only a few 3D structures of amyloid fibrils have yet been determined, ${ }^{16,17}$ owing in part to the fibrils' noncrystalline, insoluble, and mesoscopically heterogeneous nature. This makes these structures difficult to access by established structural techniques such as X-ray crystallography or solution-state NMR. ${ }^{18}$ Since the 1970 s, amyloid has been defined by its main $\beta$-sheet fibrillary structure, ${ }^{19-21}$ and by properties associated with this. The unifying structure is an assembled protein fibril in which the sheets are parallel to the fibril direction and where the strands run perpendicular to the fibril. This principal organization is believed to be common to all amyloid fibrils, irrespective of the biochemical nature. ${ }^{13}$ 


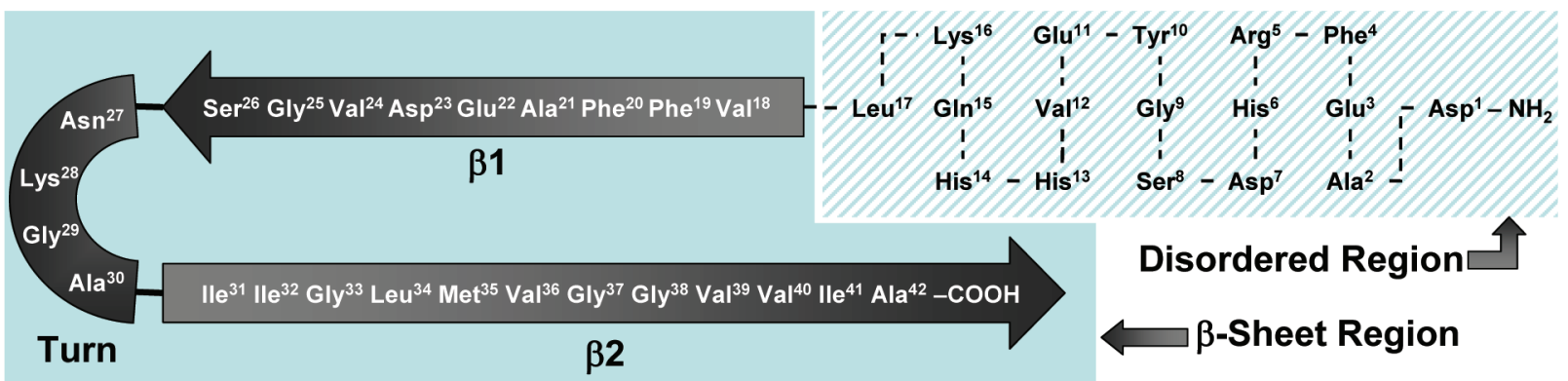

Figure 1. Amino acid sequence of human amyloid beta $1-42$ peptide $\left(\mathrm{A} \beta_{1-42}\right)$ and schematic representation of a molecule of $\mathrm{A} \beta_{1-42}$ in a hairpin shape. The residues $1-17$ comprise the disordered region. The residues $18-42$ comprise the $\beta$-sheet region.

The amyloid beta $1-42$ peptide $\left(\mathrm{A} \beta_{1-42}\right)$ fragment is the dominant $\mathrm{A} \beta$-species in the amyloid plaques of $\mathrm{AD}$ patients, and compared with the amyloid beta $1-40$ peptide $\left(\mathrm{A} \beta_{1-40}\right)$, it displays a dramatically increased propensity to form amyloid fibrils in vitro. ${ }^{22-25}$ Furthermore, a comparison of the kinetic data of $\mathrm{A} \beta_{1-40}$ and $\mathrm{A} \beta_{1-42}$ shows that $\mathrm{A} \beta_{1-40}$ adopts more varied conformational structures compared to $\mathrm{A} \beta_{1-42}$, as seen by the fluctuations of the Tyr signal displayed by $\mathrm{A} \beta_{1-40 .}{ }^{26} \mathrm{~A}$ comparative experimental-theoretical conformational study has been carried out by Sgourakis et al., ${ }^{27}$ which sheds light on the differential conformational behavior of the monomers in aqueous solution of $\mathrm{A} \beta_{1-40}$ and $\mathrm{A} \beta_{1-42}$. The presence of metal ions, in particular copper, zinc, and iron, has been reported to enhance A $\beta$ aggregation. ${ }^{28-30}$ Several important structural characteristics of $\mathrm{A} \beta_{1-42}$ fibrils have been determined, ${ }^{14-18}$ establishing that $\mathrm{A} \beta_{1-42}$ fibrils form a cross- $\beta$ structure $^{31}$ that contains parallel, in-register $\beta$-sheets. ${ }^{32}$ Most recently, it was found that memory deficits in middle-age transgenic AD model mice are caused by the extracellular accumulation of a dodecameric $\mathrm{A} \beta_{1-42}$ soluble assembly. ${ }^{12}$ While the major toxic species in AD are probably $\mathrm{A} \beta$-oligomers, thus being a principal target of $\mathrm{AD}$ drug development, it remains unclear why $\mathrm{A} \beta$-oligomers should be neurotoxic. Plausible mechanisms of toxicity include links to oxidative stress, metal binding, free radical formation, ${ }^{33}$ or ion channel formation, ${ }^{34}$ and therefore, it may be possible to interact with these processes by applying reducing agents, metal chelators, ${ }^{35}$ or ion channel inhibitiors. In general terms, an ideal approach would be to interfere with the early phases of molecular pathways that lead to the disease. Consequently, one attractive therapeutic strategy for the treatment of $\mathrm{AD}$ is to inhibit $\mathrm{A} \beta$-peptide aggregation, since this appears to be one of the first steps in the pathogenic process of amyloidosis that is not associated with some natural biological function. ${ }^{36}$ Breaking these amyloid aggregates down by nonpeptide or peptide inhibitors seems to be a promising way to combat AD. ${ }^{37}$ To that aim, it is crucial to understand the conformational and dynamic behavior of the structure of the $\mathrm{A} \beta_{1-42}$ aggregates in order to rationally design a putative $\mathrm{AD}$ drug. Moreover, the conformational analysis and the investigation of the structure of $\mathrm{A} \beta_{1-42}$ aggregates might lead to a more profound understanding of the primary pathogenesis of $\mathrm{AD}$ and comprehension of the development at the molecular level of this dramatic disease.

Most computational investigations of the structure and dynamics of $\mathrm{A} \beta$-peptides have focused on monomers, ${ }^{11,27,38-47}$ dimers, ${ }^{48-50}$ and other low-order oligomers. ${ }^{8,51-56}$ The idea of considering a full-length molecular model of the $\mathrm{A} \beta$-aggregates is worthy of consideration, since the majority of the studies mentioned above have employed models using a truncatedsequence molecular model and/or insoluble fibril state. In our present investigation, profiting from the structural information available from recent solid-state nuclear magnetic resonance
(ssNMR) experiments ${ }^{16,32,39,41,57,58}$ on the parallel cross- $\beta$ structure of $\mathrm{A} \beta$-protofilaments, we perform all-atom/explicit solvent simulations of amyloid aggregates containing three and five peptide units. Every unit with "hairpin" shaped A $\beta_{1-42}$ peptides was located in a plane roughly perpendicular to the fibril axis, as it was observed by using ssNMR. ${ }^{16}$ Among the different structural topologies possible depending on the experimental growth conditions, ${ }^{39,41,58}$ we focus on $\mathrm{A} \beta_{1-42}$ fibrils grown under the conditions defined as in ref 16 . The objectives of our study are twofold: (1) to explore the contributions of the different structural elements to the stability of full-length aggregated $\mathrm{A} \beta_{1-42}$ in solution and (2) to investigate the most promising, potential structural target for further drug design based on the structure-stability information of our model. Our reasonably long-time simulations (100 ns) of both tri- and pentameric aggregates at $310 \mathrm{~K}$, in which fibrils are experimentally stable (below $\sim 330 \mathrm{~K}$ ), permit us to draw conclusions on structurally relevant aggregate characteristics such as the secondary-toquaternary structural elements (e.g., $\beta$-strands, intra- and intermolecular contacts), internal salt-bridges, and interior hydration. In the present study, we analyze the evolution of these elements at $310 \mathrm{~K}$, focusing in particular on the structure and dynamics behavior in solution of the full-length $\mathrm{A} \beta_{1-42}$ aggregates.

\section{Methods}

System Setup. The human amyloid beta 1-42 peptide $\left(\mathrm{A} \beta_{1-42}\right)$ (Figure 1 ) was taken as a model system. The calculations were carried out using the structure of the $\mathrm{A} \beta_{1-42}$ fibrils (PDB entry 2BEG) determined by Lührs and co-workers ${ }^{16}$ that was downloaded from the Protein Data Bank. ${ }^{59}$ Due to the fact that residues $1-17$ are disordered and lacking a unique and stable conformation, we only had experimental structural information from residues $18-42 .{ }^{16}$ Therefore, in order to have the completed molecule of $\mathrm{A} \beta_{1-42}$, the sequence for the residues 1-17 was completed using an arbitrary totally extended orientation $\left(\phi \cong 180^{\circ}\right.$ and $\left.\psi \cong 180^{\circ}\right)$. Both trimeric and pentameric aggregates were investigated. The trimeric system was obtained by deletion of the edging chains of the experimental structure determined by Lührs and co-workers, ${ }^{16}$ which is a pentameric aggregate. Protons were added using the program pdb2gmx, in the GROMACS suite of programs, for optimization of the hydrogen bond network.

The peptide aggregates were embedded in a rectangular box containing SPC waters, ${ }^{60}$ leaving at least $10 \AA$ between the solutes and the edge of the box. The total number of water molecules varied between 15630 and $25919 . \mathrm{Na}^{+}$ions were added to the systems by replacing water molecules in random positions, thus making the whole system neutral (Table 1). In order to equilibrate our systems, we carried out an extensive simulated annealing (SA) protocol with repeating heating/ 
TABLE 1: Selected Parameters Used in Simulations A-E, Including Molecular Dynamics (MD) Simulation Code, Number of $A \beta_{1-42}$ Chains per System (\# $\beta A$ ), Number of $\mathrm{Na}^{+}$Ions Added for Neutrality (\# $\mathrm{Na}^{+}$), Number of Water Molecules per Simulation (\# $\mathbf{H}_{2} \mathrm{O}$ ), Total Number of Atoms per System (\#atoms), and Total Simulation Time (time, in ns)

\begin{tabular}{ccrrrr}
\hline $\mathrm{MD}$ & $\# \beta \mathrm{A}$ & \# Na $^{+}$ & ${\text {\# } \mathrm{H}_{2} \mathrm{O}}$ & \# atoms & time \\
\hline $\mathrm{A} 3$ & 3 & 9 & 17284 & 53742 & 20 \\
$\mathrm{~B} 3$ & 3 & 9 & 17284 & 53742 & 20 \\
$\mathrm{C} 3$ & 3 & 9 & 17302 & 53796 & 20 \\
$\mathrm{D} 3$ & 3 & 9 & 15630 & 48780 & 20 \\
$\mathrm{E} 3$ & 3 & 9 & 17284 & 53742 & 100 \\
$\mathrm{~A} 5$ & 5 & 15 & 25919 & 80907 & 20 \\
$\mathrm{~B} 5$ & 5 & 15 & 21200 & 66750 & 20 \\
$\mathrm{C} 5$ & 5 & 15 & 20832 & 65646 & 20 \\
$\mathrm{D} 5$ & 5 & 15 & 20832 & 65646 & 20 \\
$\mathrm{E} 5$ & 5 & 15 & 20009 & 63177 & 100
\end{tabular}

cooling cycles covering a broad temperature range (from 310 up to $500 \mathrm{~K}$ ), in which fibrils are experimentally stable (below $\sim 330 \mathrm{~K}$ ) or fully dissociated (above $\sim 373 \mathrm{~K}$ ) ${ }^{61,62}$ During the whole minimization position, restraint was applied for the alpha carbons $\left(\mathrm{C}^{\alpha}\right)$ of residues $18-42$. As a result of the SA runs, the disordered region (DR) residues showed a large range of conformational sampling. Multiple simulations were performed for each system, starting from different initial random velocity distributions, generating five independent strands of simulations (labeled A-E, see Table 1). Details of the equilibration procedure can be found in the Supporting Information. For each strand between 20-100 ns, production runs were obtained and analyzed. The coordinates were saved every 2 ps.

Simulation Parameters. All simulated annealing (SA) simulations and molecular dynamics (MD) simulations were performed using the GROMACS 3.3.2 package of programs, ${ }^{63}$ with the OPLS-AA force field. ${ }^{64}$ The simulations were run under NPT conditions, using Berendsen's coupling algorithm ${ }^{65}$ for keeping the temperature and pressure constant $\left(P=1\right.$ bar, $\tau_{\mathrm{P}}$ $=0.5 \mathrm{ps} ; T=310$ or $\left.500 \mathrm{~K}, \tau_{\mathrm{T}}=0.1 \mathrm{ps}\right)$. The LINCS algorithm $^{66}$ was used to constrain the lengths of hydrogen containing bonds; the waters were restrained using the SETTLE algorithm. ${ }^{67}$ A force constant of $1000 \mathrm{~kJ} \mathrm{~mol}^{-1} \mathrm{~nm}^{-1}$ was used for position restraints during the SA. For the subsequent unrestrained MD simulations, the same parameters were used as for the restrained $\mathrm{MD}$, except that the temperature was maintained at $310 \mathrm{~K}$ and no positional restraints were applied. The time step for the simulations was $0.002 \mathrm{ps}$ and the compressibility $4.8 \times 10^{-5}$ bar $^{-1}$. van der Waals forces were treated using a $1.2 \mathrm{~nm}$ cutoff. Long-range electrostatic forces were treated using the particle mesh Ewald method (PME). ${ }^{68}$

Analysis. The analysis of the simulations was performed using the analysis tools provided in the Gromacs package. The root mean square deviation ( $\mathrm{rmsd}$ ) of backbone atoms and the total and potential energies were calculated. The root mean square fluctuation (rmsf) of the backbone atoms and the hydrophilic, hydrophobic, and total solvent accessible surface area (SASA) were also determined. The total number of hydrogen bonds in the peptide group was quantified by counting acceptor and donor atom pairs that are not further apart than $0.35 \mathrm{~nm} .{ }^{69}$ Secondary structure analysis used DSSP. ${ }^{70}$ All molecular graphical presentations were created by $\mathrm{VMD}^{71}$ and/ or UCSF Chimera ${ }^{72}$ packages. The standard deviation of every given value is shown in parentheses.

\section{Results and Discussion}

To more clearly present the results obtained with our simulations, we have divided our system into two regions. The first region encompasses residues $1-17$, which is very likely to be a region with a large degree of flexibility. We will refer to this region as the "disordered region" (DR). The second region comprises residues $18-42$, which is the $\beta$-sheet region $(\beta \mathrm{R})$. The $\beta \mathrm{R}$ presents a $\beta$-strand-turn- $\beta$-strand motif (hooklike or hairpin shape) that contains two intermolecular, parallel, in-register $\beta$-sheets that are formed by residues $18-26(\beta 1)$ and $31-42(\beta 2)$ connected by a turn formed by residues $27-30^{16}$ (Figure 1). Figure 2 shows the superposition of five structures collected every $2 \mathrm{~ns}$ of SA of the pentameric system, which form the starting structures of the five independent simulations performed (denoted strands $\mathrm{A}-\mathrm{E}$ ). In Figure 2, a high degree of mobility of the DR is clearly visible. A similar result was observed for the trimeric system. Using the final structures obtained by the simulated annealing (SA) protocol as starting structures for the MD simulations, we initially generated $20 \mathrm{~ns}$ trajectories for each of the strands. Although the potential energies of the systems quickly equilibrate over a period of 100 ps (see Figure S3, Supporting Information), it became clear that $20 \mathrm{~ns}$ is too short to reach equilibrium in the overall structural properties of the aggregates, e.g., $\beta$-helix formation. Therefore, we extended two of the simulations, for both the trimeric and pentameric systems, to $100 \mathrm{~ns}$. The first $20 \mathrm{~ns}$ of these simulations is considered equilibration time. The results described and discussed in the remaining part of this paper are mainly based on the extended simulations, corresponding to string E; nevertheless, strings $\mathrm{A}-\mathrm{D}$ have shown similar results. Figure 3 shows snapshots of the trimeric and pentameric aggregates at 0 and $100 \mathrm{~ns}$ of simulation. Top and lateral views are shown. The average values of the properties (e.g., rmsd and angles) are calculated only considering the last $80 \mathrm{~ns}$ of the simulations. Figure 4 displays the evolution of rmsd's and rmsf's for the E simulations. As a general feature, it can be observed that the trimeric system compared to the pentameric form displays a higher flexibility. Parts A and C of Figure 4 show the evolution of the rmsd for the DR and the $\beta \mathrm{R}$ (and its subdivisions; $\beta 1$, turn, and $\beta 2$ ) for simulations E3 and E5. The portions $\beta 1$ and turn showed the higher fluctuations of rmsd. This flexibility can also be appreciated in parts B and D of Figure 4, which show the rmsf values per residue per chain. It was observed in all simulations (strings $\mathrm{A}-\mathrm{E}$ ) and as a general feature that the trimeric aggregate is structurally more flexible than the pentamer. This fact may be attributed to the higher degree of packing that a pentameric aggregate has in comparison with the trimeric one. Especially in the case of the trimeric aggregate, generally large fluctuations in rmsd occurred for the $\beta 1$ and turn portions with an average value of $0.43(0.06)$ and $0.44 \mathrm{~nm}(0.08)$, respectively. On the other hand, it is interesting to note that the $\beta 2$ portion reached an average rmsd value of $0.34 \mathrm{~nm}(0.02)$ after $\sim 12 \mathrm{~ns}$ of simulation (Figure $4 \mathrm{~A}$ ). This can be correlated with the formation of a $\beta$-helix structure in this portion of the aggregate. Nevertheless, in the case of pentameric aggregates, generally no large rmsd fluctuations were observed. For pentamers, the largest rmsd value was observed for the $\beta 1$ portion with $0.41 \mathrm{~nm}(0.03)$, while the turn portion revealed the smallest rmsd value of $0.24 \mathrm{~nm}(0.03)$. The $\beta 2$ portion showed an average rmsd value of $0.30 \mathrm{~nm}(0.03)$ (Figure 4C) which was smoothly reached after $20 \mathrm{~ns}$ of simulation, and which can be attributed to the formation of a $\beta$-helix structure in this portion of the aggregate. A good correlation with what was observed for rmsd profiles can be appreciated in parts B 


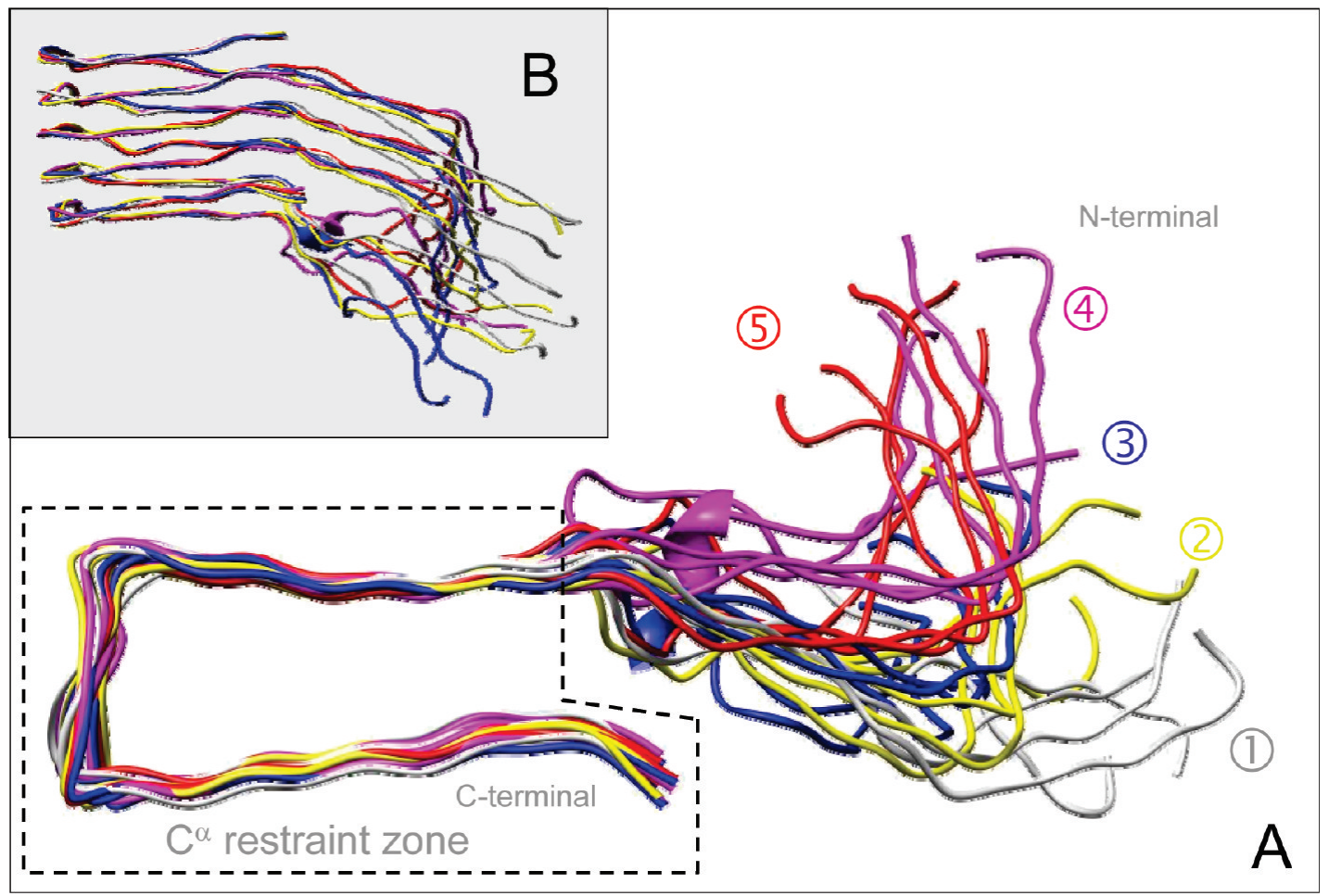

Figure 2. Overlapped stereoviews of five configurations collected every $2 \mathrm{~ns}$ of simulation from the simulated annealing of the pentameric aggregate: (A) top view indicating the $\mathrm{C}^{\alpha}$ position restraint zone; (B) lateral view.

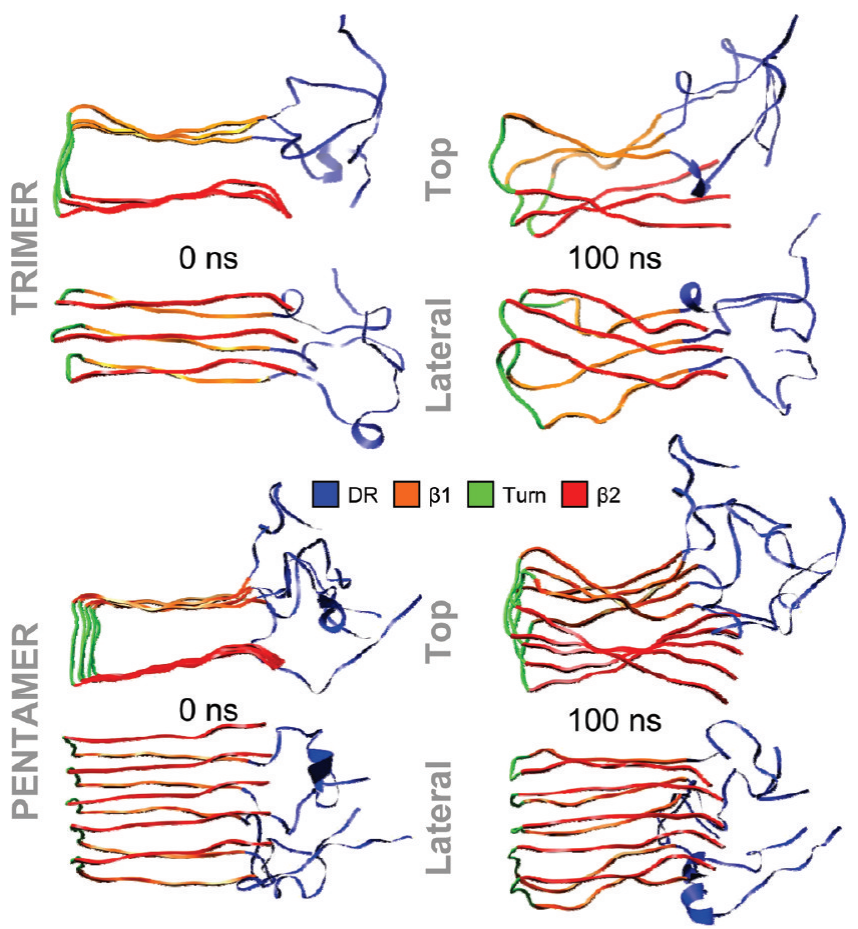

Figure 3. Snapshots at 0 and $100 \mathrm{~ns}$ of simulation of the trimeric and pentameric aggregates. Top and lateral views are shown.

and D of Figure 4, which show the rmsf values for each portion of the trimeric and pentameric aggregate, respectively. The highest rmsf values were observed for amino acid residues located in the DR, $\beta 1$, and turn portions for the trimeric aggregate, while for the pentameric aggregate this was mainly seen in DR and $\beta 1$ portions (Figure $4 \mathrm{~B}$ and D). Interestingly, in the vicinity of each Gly residue (residues 9, 25, 29, 33, 37, and 38), rmsf values increased due to the natural lack of side chains of this amino acid residue. It is worth noting that the lowest RMDF values, in all simulations for both trimeric and pentameric aggregates, were observed for those amino acid residues located in the $\beta 2$ portion.

Figure 5A and B illustrates the temporal development of the secondary structure content for the trimeric and pentameric aggregates, along the $100 \mathrm{~ns}$ trajectory. In Table 2, the secondary structure content for the $\mathrm{DR}$ and $\beta \mathrm{R}$ is summarized. For all simulations, both $\beta 1$ and $\beta 2$ portions are stable at room temperature for the duration of the simulations. Even peptides located at the ends of the aggregate present stable $\beta$-strand regions, with the occasional loss of $\beta$-sheet content in the $\beta 1$ portion. A small content of $\alpha$-helix and $3^{10}$-helix structures is infrequently observed for the DR. These kinds of helices are notably present with peptides at the edge of the aggregate. As a general phenomenon, the loss of structure is more pronounced in the trimeric aggregates, indicating that, at least at the finite lengths studied here, they are more structurally flexible than the pentamers. The loss of structure, especially of the $\beta$-strand motifs, of peptides from the aggregate ends seems to start at the $\beta 1$ and in the turn portions, while the core of the aggregate comprised of the $\beta 2$ portion remains largely intact. On the other hand, transient helical conformations in the $\mathrm{N}$-terminal residues (Figure 5) were also reported in previous fibril formation experiments and simulations. ${ }^{45,49,73,74}$ Figure 6 shows the average interchain distances of the mass center of the $C^{\alpha}$ s at the various regions of our systems. A large fluctuation can be appreciated for the turn portion in simulation E3, which suggests a great mobility in this portion of the aggregate. The DR showed an average value of $0.77 \mathrm{~nm}(0.04)$, which is also slowly reached (after $\sim 40 \mathrm{~ns}$ ) by the $\beta 1$ portion with an average of $0.72 \mathrm{~nm}$ (0.09), indicating that these two parts of the molecule behave similarly with respect to interchain mobility. It is interesting to note the great influence that the DR has over the $\beta 1$ portion. The $\beta 2$ portion showed the lowest fluctuation as compared to the other portions, and also the lowest average value of 0.42 $\mathrm{nm}$ (0.03), suggesting a low interchain mobility and a great 

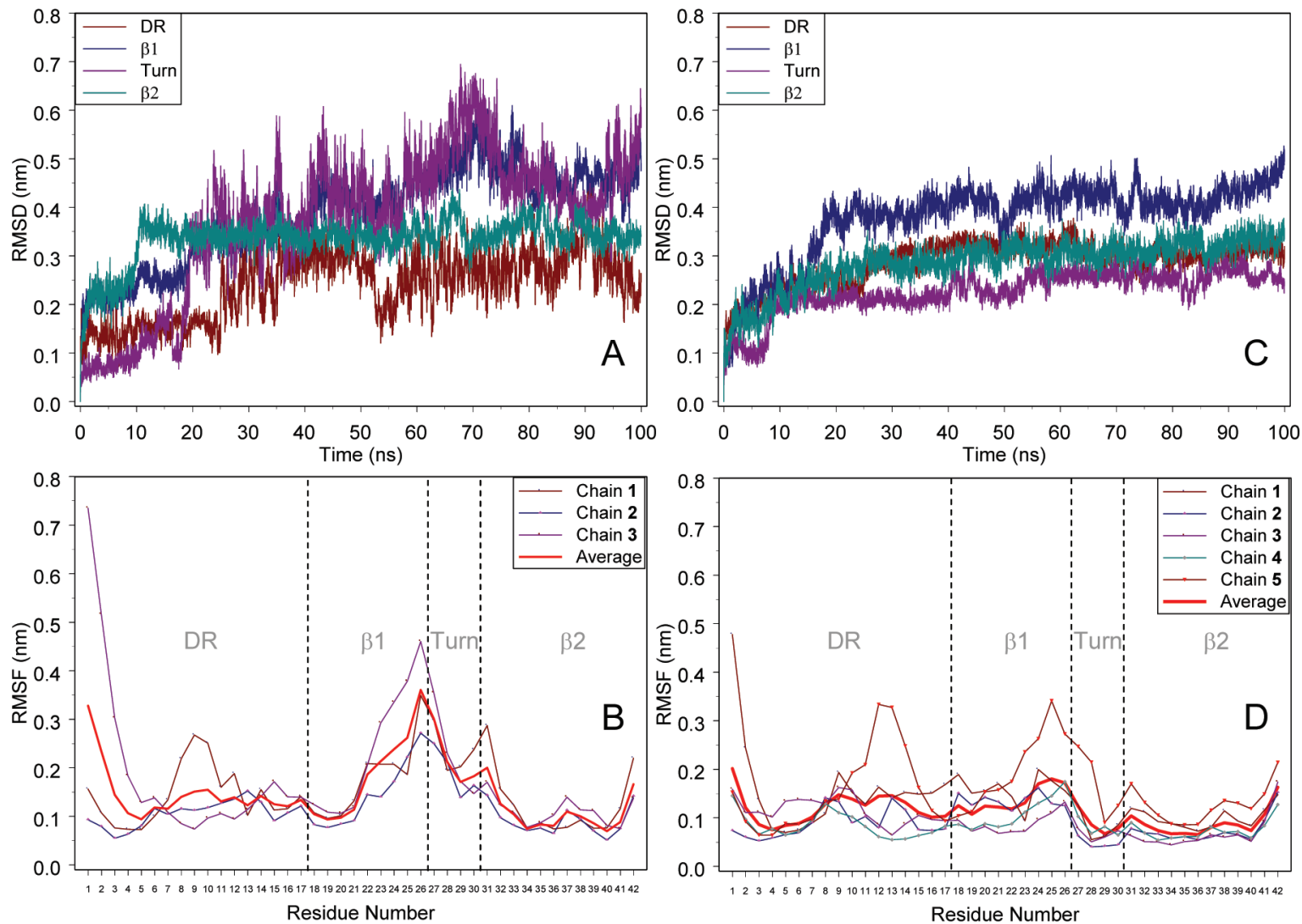

Figure 4. $\mathrm{C}^{\alpha}$ root mean square deviation (rmsd) and root mean square fluctuation (rmsf) as a function of time and plotted against the number of residues for $(\mathrm{A}$ and $\mathrm{B})$ trimeric aggregate and $(\mathrm{C}$ and $\mathrm{D})$ pentameric aggregate.

compactness in this portion (Figure 6A). A very similar pattern was observed for the pentameric aggregate of the $\beta 2$ portion with respect to mobility and compactness. In this case, an average value of $0.45 \mathrm{~nm}(0.01)$ was rapidly and smoothly reached (Figure 6B). On the other hand, the DR region showed a general trend toward a larger interchain distance $(1.21 \mathrm{~nm}$ (0.02) for simulation E5), while the $\beta 1$ portion did not follow the same pattern as the DR which we found for the trimeric aggregate. Therefore, the $\beta 1$ portion in the pentameric configuration appears to be more compact $(0.66 \mathrm{~nm}(0.04))$ than the $\beta 1$ portion of the trimeric aggregate. Interestingly, the turn portion in the pentamers showed a smaller fluctuation than the same portion in the trimers, suggesting that this as well as the $\beta 1$ portion has a lower interchain mobility and a higher compactness $(0.53 \mathrm{~nm}(0.02))$ in the pentameric aggregate. Very similar interchain distances in the center of mass were seen for the $\mathrm{C}^{\text {carbonyl' }}$ s and $\mathrm{C}^{\beta}$ 's of each portion in our system (see Figure S4, Supporting Information). These results, especially the behavior of the $\beta 2$ portion, are in good agreement with the experimental findings of Balbach et al. ${ }^{32}$ for a parallel $\beta$-sheet organization, who reported the nearest-neighbor intermolecular distances of $4.8 \pm 0.5 \AA$ for carbon sites. At this point, we emphasize the high stability observed for the $\beta 2$ portion, which suggests a possible mechanism for fibril elongation, as was previously reported. ${ }^{55}$ Hypothetically, in a first step, the initial monomer addition at the end of a growing aggregate would be driven by strong hydrophobic interactions stabilizing the $\beta 2$ portion. In a second stage, the less stable $\beta 1$ portion would form, finally followed by the more flexible turn with its relatively hydrophilic residues adopting the fibril conformation. On the other hand, it was also observed for $\mathrm{A} \beta_{1-42}$ monomers in solution that the sequence I ${ }^{31}$ IGLMVGGVVIA ${ }^{42}$ (namely, the $\beta 2$ portion) may be responsible for the higher propensity of this peptide to form amyloids. ${ }^{27}$

Consistent with ssNMR data on amyloid fibrils, ${ }^{39,41,57}$ all of our starting fibril conformations have $\mathrm{Asp}^{23} / \mathrm{Lys}^{28}$ salt-bridge contacts in the loop region. Other studies also showed that charged residues are important for the dynamics of protein aggregation and the stability of $\beta$-sheet structures. . $^{54,73,75,76}$ Consistent with previous results, ${ }^{40,55}$ our trajectories of both trimeric and pentameric aggregates reveal that the $\mathrm{Asp}^{23} / \mathrm{Lys}^{28}$ bridges are maintained at $310 \mathrm{~K}$. Figure 7 shows the distance between the center of mass of the carboxyl group of $\mathrm{Asp}^{23}$ and the center of mass of the $\mathrm{NH}_{3}{ }^{+}$group of $\mathrm{Lys}^{28}$, as well as a simplified image of the starting configuration and the configuration after $100 \mathrm{~ns}$ of simulation for the pentameric case. It can be appreciated that the positive and negative charges alternate along the fibril axis as in a one-dimensional ionic crystal. We observed that both trimeric and pentameric aggregates form intrachain salt-bridges $\left(\mathrm{Asp}_{n}{ }^{23} / \mathrm{Lys}_{n}{ }^{28}\right)$ and interchain salt-bridges $\left(\mathrm{Asp}_{n}{ }^{23} / \mathrm{Lys}_{n-1}{ }^{28}\right.$ ), where $n$ stands for the chain number. Moreover, the majority of the salt-bridges were maintained during the whole simulation time, reaching an average distance between the center of mass of the carboxyl group of $\mathrm{Asp}^{23}$ and the center of mass of the $\mathrm{NH}_{3}{ }^{+}$group of Lys $^{28}$ of $0.32 \mathrm{~nm}(0.03)$ for simulation E5, and of $0.38 \mathrm{~nm}(0.19)$ for simulation E3. Also, as illustrated in Figure 6, it can be concluded that, for those salt-bridges where $\mathrm{Asp}_{2}{ }^{23}$ took part in, an average distance of $0.58 \mathrm{~nm}(0.15)$ was reached after approximately $32 \mathrm{~ns}$, which was kept until the end of the simulation. On the other hand, salt-bridges involving $\mathrm{Asp}_{5}{ }^{23}$ were broken ( $\sim 43 \mathrm{~ns}, \mathrm{Asp}_{5}{ }^{23} / \mathrm{Lys}_{5}{ }^{28}$, Figure 7C) or displayed large fluctuations ( $\sim 50 \mathrm{~ns}, \mathrm{Asp}_{5}{ }^{23} / \mathrm{Lys}_{4}{ }^{28}$, Figure $\left.7 \mathrm{D}\right)$, since after a certain amount of simulation time this negatively charged amino 

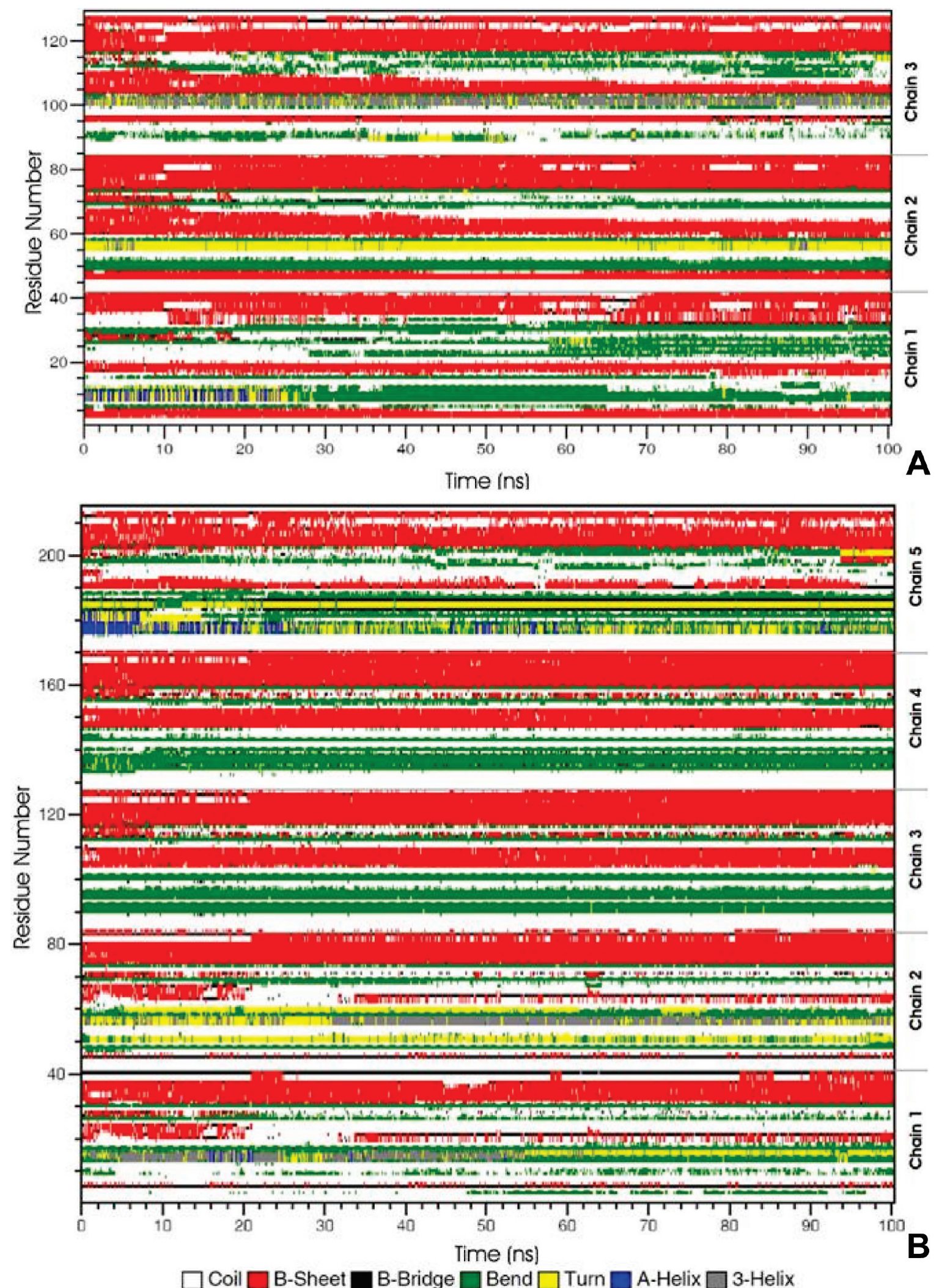

Figure 5. Change in the secondary structure during molecular dynamics simulation for both trimeric (A) and pentameric (B) model systems.

acid residue was totally solvated by molecules of water. Figure S5 in the Supporting Information shows the distance between the center of mass of the carboxyl group of $\mathrm{Asp}^{23}$ and the center of mass of the $\mathrm{NH}_{3}{ }^{+}$group of $\mathrm{Lys}^{28}$ for the trimeric system. In this case, the intrachain salt-bridges and the interchain saltbridges were formed and broken over the entire simulation time. In the case of trimeric aggregates, large fluctuations occurred, salt-bridges being formed and broken over the entire simulation time, which may explain, at least in part, the higher flexibility of the trimeric system compared to the pentameric conformation (Figure S5, Supporting Information). Also, as reported before for $\mathrm{A} \beta_{1-40}$ fibrils, ${ }^{40,55}$ we find narrow water channels solvating the $\mathrm{Asp}^{23} / \mathrm{Lys}^{28}$ salt-bridges within the aggregates. Indirect experimental evidence for interior hydration of $\mathrm{A} \beta$-fibrils comes 
TABLE 2: Summarized Average Percentage of the Secondary Structural Composition of the Different Regions and Portions of the A $\boldsymbol{\beta}$-Aggregates in Solution (The Average Values Shown Here Are Calculated over the Last 80 ns of Simulation $)^{a}$

\begin{tabular}{|c|c|c|c|c|c|}
\hline \multirow[b]{2}{*}{ system } & \multirow{2}{*}{$\begin{array}{l}\text { secondary } \\
\text { structure }\end{array}$} & \multirow[b]{2}{*}{ DR } & \multicolumn{3}{|c|}{$\beta \mathrm{R}$} \\
\hline & & & $\beta 1$ & turn & $\beta 2$ \\
\hline \multirow[t]{4}{*}{ trimeric } & extended $^{b}$ & $15.1(3.1)$ & $24.4(7.0)$ & 0.0 & $63.1(7.7)$ \\
\hline & helical $^{c}$ & $4.5(2.9)$ & 0.0 & 0.0 & 0.0 \\
\hline & bend $^{d}$ & $28.3(4.7)$ & $7.4(4.0)$ & $0.8(3.3)$ & $0.5(1.0)$ \\
\hline & coil $^{e}$ & $52.4(4.5)$ & $68.2(6.4)$ & $99.2(3.4)$ & $36.4(7.8)$ \\
\hline \multirow[t]{4}{*}{ pentameric } & extended ${ }^{b}$ & $5.2(1.3)$ & $29.3(5.3)$ & $6.5(5.8)$ & $63.7(4.4)$ \\
\hline & helical $^{c}$ & $4.4(3.1)$ & 0.00 & 0.00 & 0.00 \\
\hline & bend $^{d}$ & 36.1 (3.6) & $0.6(1.1)$ & $0.7(2.3)$ & 0.00 \\
\hline & $\mathrm{coil}^{e}$ & $54.2(2.1)$ & $70.1(5.5)$ & $92.7(6.1)$ & $36.3(4.4)$ \\
\hline
\end{tabular}

${ }^{a}$ The standard deviation is given in parentheses. ${ }^{b}$ Extended $=$ $\beta$-strand $+\beta$-bridge. ${ }^{c}$ Helical $=\alpha$-helix $+3{ }^{10}$-helix $(3$-helix $)+$ $\pi$-helix (5-helix). ${ }^{d}$ Bend $=$ turns type I-IV + bend. ${ }^{e}$ Coil $=$ unstructured.
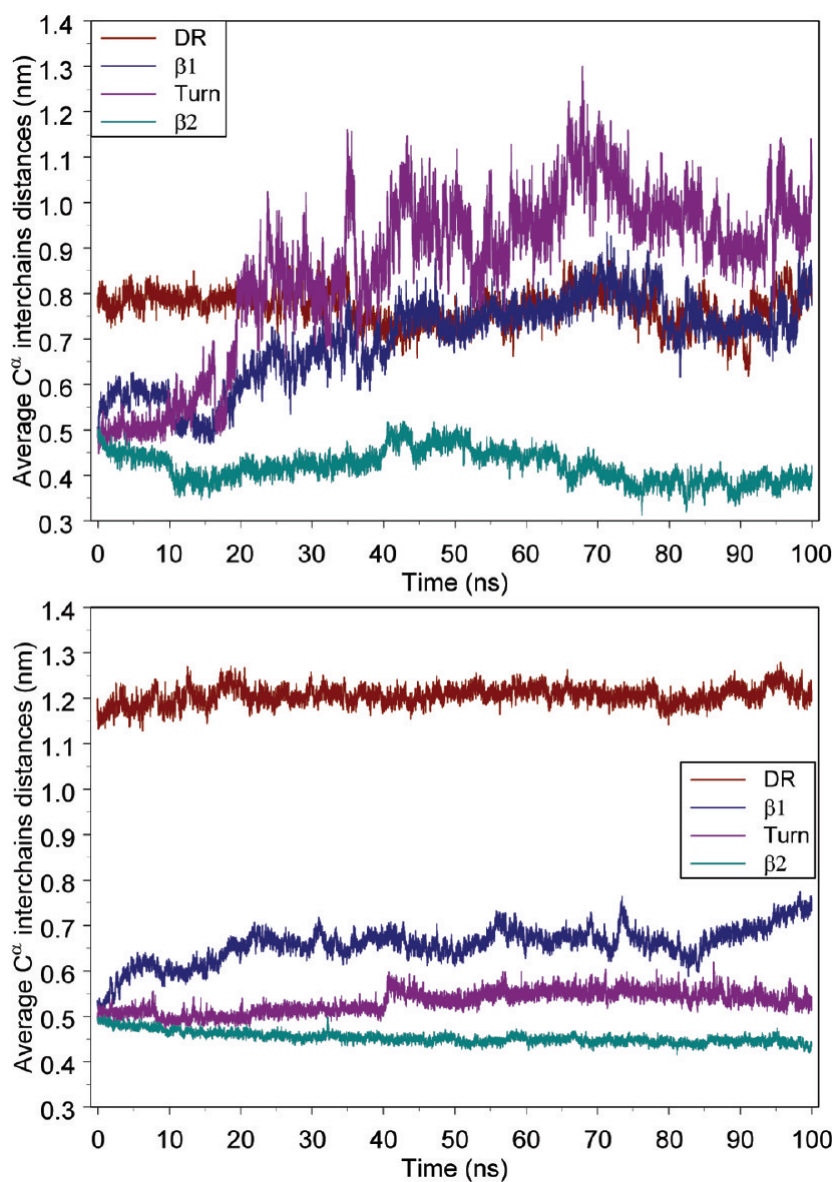

Figure 6. Average interchain distances of the mass center of the $\mathrm{C}^{\alpha}$ 's versus time of the different regions and portions of the trimeric (A) and pentameric (B) system.

from differential scanning calorimetry, ${ }^{62}$ although ssNMR data do not indicate large structural differences between lyophilized and wet fibrils. ${ }^{39,58}$ Visual inspection reveals the formation of narrow water channels solvating the interior $\mathrm{Asp}^{23} / \mathrm{Lys}^{28}$ saltbridges into the aggregates. Recent simulations of fibrils with up to $32 \mathrm{~A} \beta_{16-22}$ peptides in antiparallel $\beta$-strands have also shown similar water channels hydrating the $\mathrm{Lys}^{16} / \mathrm{Glu}^{22}$ side chains. ${ }^{56}$ In several instances, we noted an exchange in the saltbridge partners from the initial $\mathrm{Asp}^{23} / \mathrm{Lys}^{28}$ pair to $\mathrm{Glu}^{22} / \mathrm{Lys}^{28}$ as the end peptides begin to dissociate from the aggregates (Figure S6, Supporting Information). Figure S6 in the Supporting
Information displays the distance between the center of mass of the carboxyl group of $\mathrm{Glu}^{22}$ and the center of mass of the $\mathrm{NH}_{3}{ }^{+}$group of $\mathrm{Lys}^{28}$ for the intrachain salt-bridges $\left(\mathrm{Glu}_{n}{ }^{22}\right.$ / $\left.\mathrm{Lys}_{n}{ }^{28}\right)$ and the interchain salt-bridges $\left(\mathrm{Glu}_{n}{ }^{22} / \mathrm{Lys}_{n-1}{ }^{28}\right)$ for the pentameric case. The presence of $\mathrm{Glu}^{22} / \mathrm{Lys}^{28}$ salt-bridges has been suggested for small $\mathrm{A} \beta$-peptide aggregates, $\mathrm{A} \beta$-monomers in solution, ${ }^{38,45,77,78}$ and $\mathrm{A} \beta_{1-40}$ fibrils. ${ }^{55}$ The $\mathrm{Glu}^{22} / \mathrm{Lys}^{28}$ ion pair might play an important role in the aggregate elongation. ${ }^{55}$ Overall, on the basis of our own and other previous studies, the main driving force for fibril elongation appears to be the formation of C-terminal $\beta$-sheets (our $\beta 2$ portion). This hypothesis seems to be supported by recent experiments showing that perturbing the hydrogen bonds in the $\beta 1$ and $\beta 2$ portions through selective $\mathrm{N}$-methylation affects both fibril growth and structure. ${ }^{43}$ Disrupting the backbone hydrogen bonds of the $\beta 1$ portion resulted in relatively slow growth of fibrils with a blurred boundary, while derangement of the $\beta 2$ hydrogen bonds had less effects on fibril growth and yielded fibrils with a sharply defined surface. These experimental results are consistent with our simulation findings.

Figure 8 displays the formation of a $\beta$-helix structure occurring especially on the $\beta 2$ portion of the pentamers. In order to quantify the twist of this $\beta$-helix motif, two dihedral angles were defined, namely, $\gamma$ and $\delta$. Using as a pivot the amino acid residue $\mathrm{Val}^{36}$, which encompasses the $\beta 2$ portion of our model, the definition of the $\gamma$ angle involves the $\mathrm{C}^{\alpha}$ 's of residues $\mathrm{Ile}_{n}{ }^{31}$, $\mathrm{Val}_{n}{ }^{36}, \mathrm{Val}_{n-1}{ }^{36}$, and $\mathrm{Ile}_{n-1}{ }^{31}$, while the definition of the $\delta$ angle involves residues $\mathrm{Ala}_{n}{ }^{42}, \mathrm{Val}_{n}{ }^{36}, \mathrm{Val}_{n-1}{ }^{36}$, and $\mathrm{Ala}_{n-1}{ }^{42}$. Parts A and $\mathrm{B}$ of Figure 8 show a spatial view of the $\beta 2$ portion at 0 and $100 \mathrm{~ns}$ of simulation time, respectively. Top views (Figure 8A1 and B1) and lateral views (Figure 8A2 and B2) are also shown. Parts $\mathrm{C}$ and $\mathrm{D}$ of Figure 8 illustrate the temporal development of the $\gamma$ and $\delta$ angles, respectively.

The $\beta$-helix is a plausible structural motif for amyloid fibrils, since it is primarily a $\beta$-sheet structure with the proper cross- $\beta$ orientation $^{79-82}$ and known to occur in bona fide proteins. As described above, in our model of $\mathrm{A} \beta_{1-42}$ aggregates in solution, the formation of a $\beta$-helix structure occurred especially on the $\beta 2$ portion (Figure 8 ). The model used by us is an elaboration of the classical cross- $\beta$ molecular structure, which permits the incorporation of the favorable twisted $\beta$-sheet structures. This kind of helical structure enables the hydrogen bonding between the $\beta$-strands to be extended over the total length of the amyloid fibrils, thereby accounting for their characteristic rigidity and stability. ${ }^{15}$ Increased fibril twisting could be caused by the loss of directional hydrogen bonding, and a gain in packing interactions. ${ }^{83}$ A schematic definition of those angles is shown in Figure 8A. In general, after approximately $20 \mathrm{~ns}$ of simulation, an average value of $-8.95^{\circ}(0.97)$ and $-9.40^{\circ}$ (1.93) was reached for $\gamma$ and $\delta$, respectively. In Figure $8 \mathrm{C}$, a great fluctuation for the $\delta$ angle can be observed. This may be caused by the fact that the definition of this angle involves the $\mathrm{C}^{\alpha}$ of the terminal residues $\mathrm{Ala}^{42}$, which are in direct contact with the solvent and therefore leading to a greater mobility. Since twisted $\beta$-sheets optimize the hydrogen bonds, side-chain stacking, and electrostatic interactions, it is commonly accepted that twisted sheets are more stable than flat ones. This result is in good agreement with those reported by Periole et al. that shows the formation of a cross- $\beta$ by the peptide GNNQQNY with a twist ranging from 0 to $12^{\circ}$ per peptide around its axis when fully solvated. ${ }^{84}$

Although our model is a full-length model for $\mathrm{A} \beta_{1-42}$ aggregates in solution, it is of interest to compare our results to other proposed truncated and/or full-length models for $\mathrm{A} \beta_{1-40}$ 


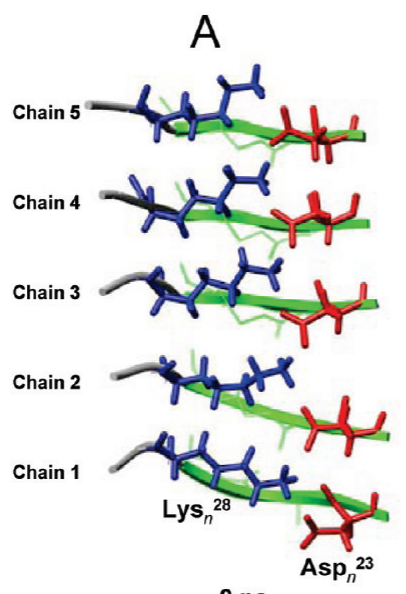

0 ns

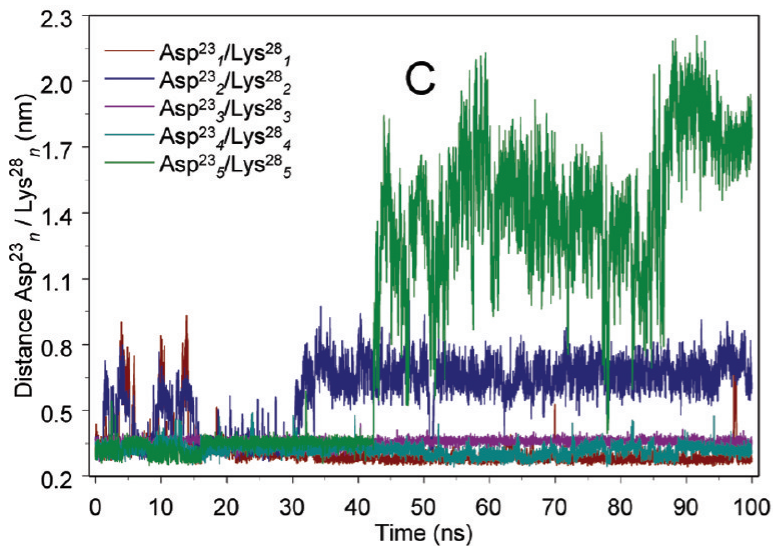

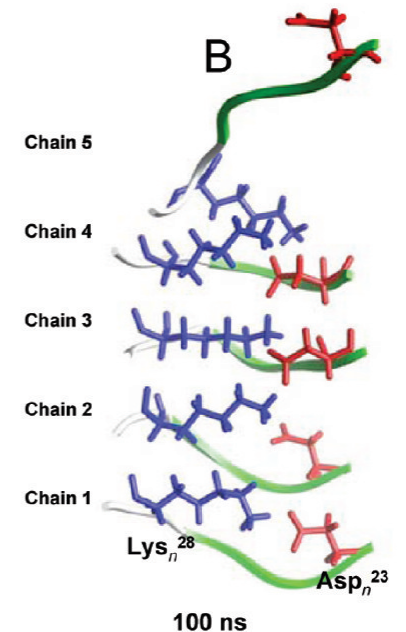

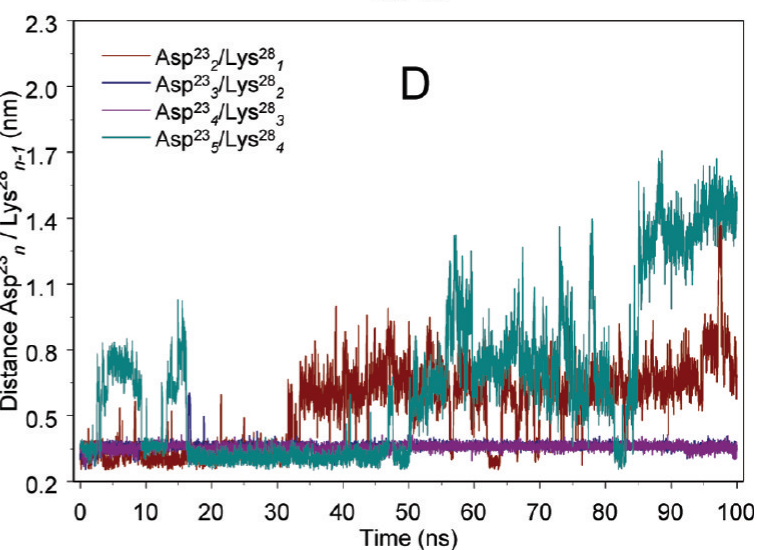

Figure 7. Simplified image of the starting configuration (A) and the final configuration (B) after 100 ns of the interaction $\mathrm{Asp}^{23} / \mathrm{Lys}^{28}$ for the

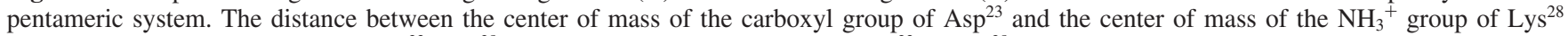
versus time for the interactions $\mathrm{Asp}_{n}{ }^{23} / \mathrm{Lys}_{n}{ }^{28}\left(\mathrm{C}\right.$; intrachain salt-bridge) and $\mathrm{Asp}_{n}{ }^{23} / \mathrm{Lys}_{n-1}{ }^{28}$ (D; interchain salt-bridge), where $n$ stands for the peptide chain number, is also shown.

structures. The so-called Tycko model ${ }^{39}$ and the LECB model ${ }^{85}$ are similar to our model, specifically, regarding the hairpin shape of the aggregates. There is a slight difference between our model and the Tycko model. Our model forms a hydrophobic core with $\mathrm{Leu}^{34}$ facing the interior of the aggregate in the $\beta 2$ portion, whereas in Tycko's model the $\mathrm{Leu}^{34}$ faces outside. In our model, it was observed that the residues Leu ${ }^{34}$ and $\mathrm{Val}^{36}$ of the portion $\beta 2$ formed an inner hydrophobic core in the aggregates. Regarding this matter, our model is more similar to the LECB model than Tycko's. The internal $\mathrm{Asp}^{23} / \mathrm{Lys}^{28}$ salt-bridge interaction is supported by experimental and theoretical data. ${ }^{16,39,54,57,85}$ This interaction has been observed in our model, as well as in the above-mentioned models. We note that the position of the turn in our model differs from the position of the same moiety in the LECB model. The turn portion encompasses the residues $\mathrm{Asn}^{27}-\mathrm{Ala}^{30}$ in our model, while the same portion encompasses the residues $\mathrm{Val}^{24}-\mathrm{Asn}^{27}$ in the LECB model. As a result of this organization, the $\mathrm{Asp}^{23} / \mathrm{Lys}^{28}$ salt-bridge shows a slight difference between the LECB model and our model. In the LECB model, the Asp ${ }^{23}$ residue is located in one of the $\beta$-strands of the peptide, and the $\mathrm{Lys}^{28}$ residue is located in the other $\beta$-strand segment; therefore, the $\mathrm{Asp}^{23} / \mathrm{Lys}^{28}$ interaction occurs in between the two $\beta$-strand portions of this model. In our model, the $\mathrm{Asp}^{23}$ is located in the $\beta 1$ portion, while the $\mathrm{Lys}^{28}$ is located in the turn portion. A closely related structural model for $\mathrm{A} \beta_{1-40}$ fibrils has been proposed by Wetzel et al ${ }^{86,87}$ In agreement with our model, Wetzel's model places the side chains of $\mathrm{Phe}^{19}$, $\mathrm{Ile}^{32}$, $\mathrm{Leu}^{34}$, and $\mathrm{Val}^{36}$ in the interior of a single molecular layer. In contrast to our model, side chains of $\mathrm{Asp}^{23}$ and $\mathrm{Lys}^{28}$ are on the exterior of a single molecular layer. A highly similar molecular organization has been described for another peptide with amyloidogenic properties. The molecular structural organization of the CA150.WW2 protofilament ${ }^{79}$ is stabilized by interdigitated hydrophobic regions, as well as by the presence of a intrachain salt-bridge between the $\mathrm{Glu}^{7}$ and $\mathrm{Arg}^{24}$ in a parallel $\beta$-sheet arrangement. This structural model has similarities to those reported for aggregates of the $\mathrm{A} \beta_{1-40}{ }^{57}$ and $\mathrm{A} \beta_{1-42}$ peptides $^{16}$ and the structure reported for the peptide Sup35. ${ }^{82}$ Beyond the stabilization effect due to the long-range interactions (e.g., salt-bridge formation) depending on sequence composition, length, and environmental conditions, the interdigitating hydrophobic sidechain interactions of the aggregates seem to be a commonly recurring feature of these aggregates.

In summary, the contributions of the different structural elements of the full-length $\mathrm{A} \beta_{1-42}$ aggregates in solution to their stability and conformational dynamics were explored. Using multiple 20-100 ns long MD simulations of fibril systems of $\sim 60000$ atoms, we studied aggregate models that differ in the quantity of peptide chains, notably pentameric and trimeric aggregates. We found that our models are stable at a temperature of $310 \mathrm{~K}$, and converge toward an interdigitated side-chain packing for intermolecular contacts within the two parallel $\beta$-sheet regions of the aggregates, $\beta 1$ (residues 18-26) and $\beta 2$ (residues 31-42). In spite of the fact that those chains at the edge of the aggregates showed a higher mobility than those chains near the aggregate core, the $\beta$-sheet region kept its arrangement ( $\beta 1$-turn- $\beta 2 /$ hairpin shape) during the entire simu- 

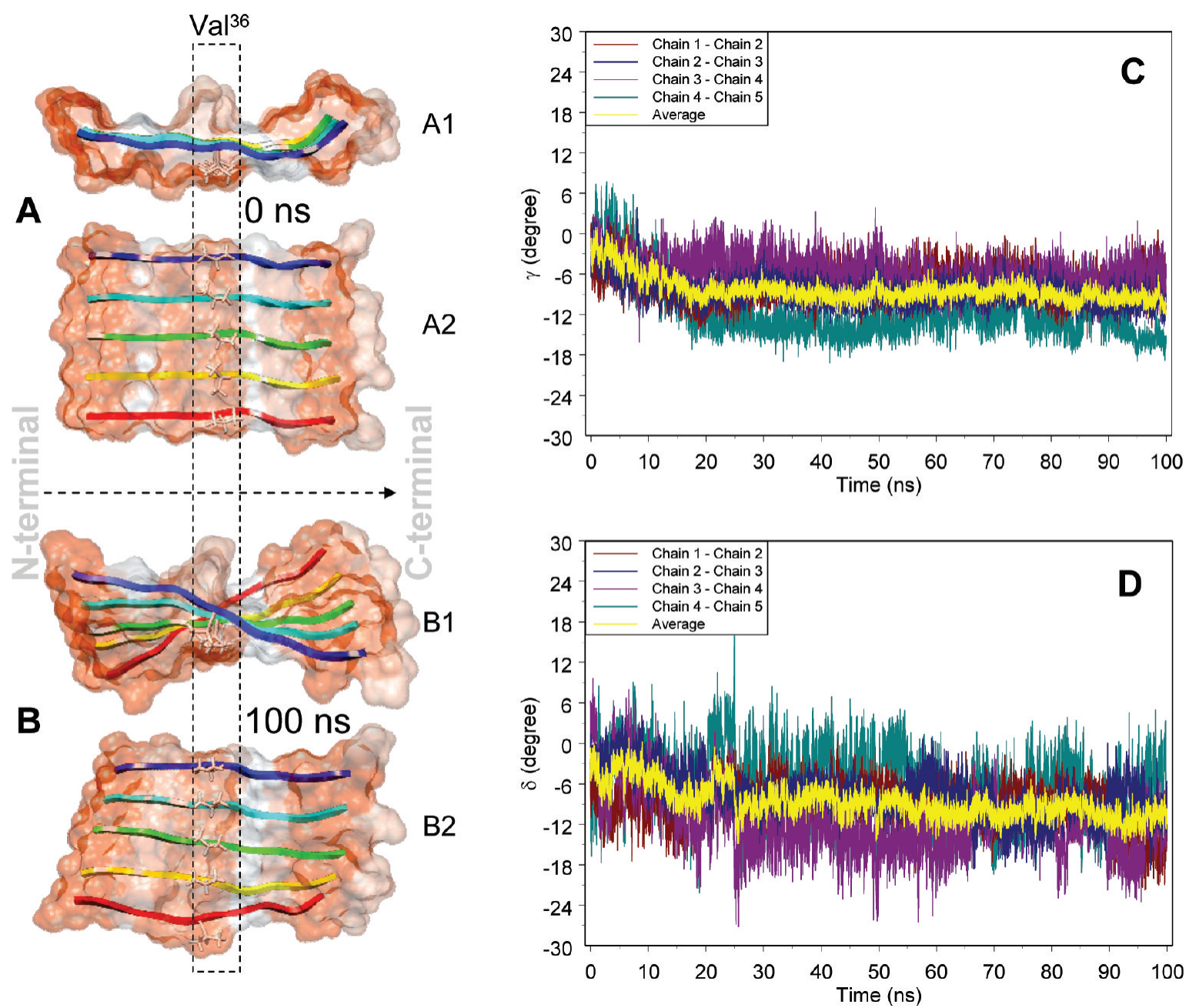

Figure 8. Simplified images of the starting configuration (A1, top view; A2, lateral view) and the final configuration (B1, top view; B2, lateral view) after $100 \mathrm{~ns}$ of the $\beta 2$ portion for the pentameric system. The $\gamma(\mathrm{C})$ and $\delta(\mathrm{D})$ dihedral angles versus time are also shown. The definition of the $\gamma$ dihedral angle involves the $\mathrm{C}^{\alpha}$ 's of residues $\mathrm{Ile}_{n}{ }^{31}, \mathrm{Val}_{n}{ }^{36}, \mathrm{Val}_{n-1}{ }^{36}$, and $\mathrm{Ile}_{n-1}{ }^{31}$, while the definition of the $\delta$ dihedral angle involves residues $\mathrm{Ala}_{n}{ }^{42}, \mathrm{Val}_{n}{ }^{36}, \mathrm{Val}_{n-1}{ }^{36}$, and $\mathrm{Ala}_{n-1}{ }^{42}$, where $n$ stands for the number of the peptide chain.

lation time. The $\beta 1$ portion showed to be more flexible than the $\beta 2$ portion, which may well be induced by the proximity of the disordered region to the $\beta 1$ portion. This provides good arguments to study the full-length $\mathrm{A} \beta$-models, since the dynamic behavior of a determinate portion of the aggregate can affect the behavior of its surroundings. The $\mathrm{Asp}^{23} / \mathrm{Lys}^{28}$ salt-bridges maintain a stable and relatively rigid interdigitated structure. However, during the initial stages of fibril dissociation, the $\mathrm{Asp}^{23} / \mathrm{Lys}^{28}$ contacts in $\mathrm{A} \beta$-peptides at the aggregate ends can break to form the competing $\mathrm{Glu}^{22} / \mathrm{Lys}^{28}$ interaction. Thus, it suggests that the loss of $\mathrm{Glu}^{22} / \mathrm{Lys}^{28}$ contacts could be an important indicator for the transition of the $\mathrm{A} \beta$-peptides from their solution structures toward the aggregated conformations. ${ }^{45,55}$ Our whole molecule simulations reveal that the $\beta$-strand twist is a characteristic element of $\mathrm{A} \beta$-aggregates, permitting a compact, interdigitated packing of side chains from neighboring $\beta$-sheets. The $\beta 2$ portion formed a very well organized $\beta$-helix, whereas the $\beta 1$ portion did not reach such a high level of organization, although it maintained its $\beta$-sheet conformation.

\section{Conclusions}

This study demonstrates the importance of studying the fulllength $\mathrm{A} \beta$-aggregates in solution in order to have a more general view of how each part of the aggregate influences the conformational behavior of the whole system. Moreover, these simulations suggest that the hydrophobic core comprising the $\beta 2$ portion of the aggregate is a crucial stabilizing element in the process of aggregation and possibly in the elongation of $\mathrm{A} \beta$-aggregates. For that reason, the $\beta 2$ portion appears to be a promising target for further drug design based on the structurestability information, such as new potential "amyloid inhibitors" capable of interacting specifically with this portion of the aggregates.

Acknowledgment. The studies described in this paper were partially performed under the Project HPC-EUROPA (RII3-CT2003-506079), with financial support of the European Community - Research Infrastructure Action of the FP6 Programme. The authors thank Mrs. Laura Leistikow of HPC-EUROPE for assistance, Ferenc Bogár, Gábor Paragi, and Máté Labádi for their technical support, and Aldo Rampioni and Xavier Periole for helpful discussions. M.F.M. is a recipient of a Fellowship of the University of Groningen. R.D.E. is a member of CONICET (Argentina).

Supporting Information Available: Detailed information about the methods and six extra figures (rmsd, rmsf and interatomic distances) describing the conformational behavior, as well as the energetic profile of our systems are also given. This material is available free of charge via the Internet at http:// pubs.acs.org. 


\section{References and Notes}

(1) Lynn, D. G.; Meredith, S. C. J. Struct. Biol. 2000, 130, 153.

(2) Rochet, J. C.; Lansbury, P. T., Jr. Curr. Opin. Struct. Biol. 2000, 10,60 .

(3) Selkoe, D. J. Nature 2003, 426, 900. 140.

(4) Holtzman, D. M.; Mobley, W. C. Trends Biochem. Sci. 1991, 16,

(5) Selkoe, D. J. Nature 1999, 399, A23.

(6) Westermark, P. Amyloid 1997, 4, 216.

(7) Kisilevsky, R. J. Struct. Biol. 2000, 130, 99.

(8) Zheng, J.; Jang, H.; Ma, B.; Tsai, C. J.; Nussinov, R. Biophys. J. 2007, 93, 3046.

(9) Soto, P.; Griffin, M. A.; Shea, J. E. Biophys. J. 2007, 93, 3015.

(10) Sciarretta, K. L.; Gordon, D. J.; Meredith, S. C. Methods Enzymol. 2006, 413, 273.

(11) Sato, T.; Kienlen-Campard, P.; Ahmed, M.; Liu, W.; Li, H.; Elliott, J. I.; Aimoto, S.; Constantinescu, S. N.; Octave, J. N.; Smith, S. O. Biochemistry 2006, 45, 5503.

(12) Lesne, S.; Koh, M. T.; Kotilinek, L.; Kayed, R.; Glabe, C. G.; Yang,

A.; Gallagher, M.; Ashe, K. H. Nature 2006, 440, 352.

(13) Westermark, P. FEBS J. 2005, 272, 5942.

(14) Ritter, C.; Maddelein, M. L.; Siemer, A. B.; Luhrs, T.; Ernst, M.;

Meier, B. H.; Saupe, S. J.; Riek, R. Nature 2005, 435, 844.

(15) Tycko, R. Curr. Opin. Struct. Biol. 2004, 14, 96.

(16) Luhrs, T.; Ritter, C.; Adrian, M.; Riek-Loher, D.; Bohrmann, B.; Dobeli, H.; Schubert, D.; Riek, R. Proc. Natl. Acad. Sci. U.S.A. 2005, 102, 17342.

(17) Nelson, R.; Sawaya, M. R.; Balbirnie, M.; Madsen, A. O.; Riekel, C.; Grothe, R.; Eisenberg, D. Nature 2005, 435, 773.

(18) Thompson, L. K. Proc. Natl. Acad. Sci. U.S.A. 2003, 100, 383. 673.

(19) Eanes, E. D.; Glenner, G. G. J. Histochem. Cytochem. 1968, 16,

(20) Glenner, G. G. N. Engl. J. Med. 1980, 302, 1283.

(21) Glenner, G. G. N. Engl. J. Med. 1980, 302, 1333

(22) Burdick, D.; Soreghan, B.; Kwon, M.; Kosmoski, J.; Knauer, M.; Henschen, A.; Yates, J.; Cotman, C.; Glabe, C. J. Biol. Chem. 1992, 267, 546.

(23) Jarrett, J. T.; Berger, E. P.; Lansbury, P. T., Jr. Biochemistry 1993, $32,4693$.

(24) Jarrett, J. T.; Berger, E. P.; Lansbury, P. T., Jr. Ann. N.Y. Acad. Sci. 1993, 695, 144

(25) Riek, R.; Guntert, P.; Dobeli, H.; Wipf, B.; Wuthrich, K. Eur. J. Biochem. 2001, 268, 5930.

(26) Vestergaard, M.; Kerman, K.; Saito, M.; Nagatani, N.; Takamura, Y.; Tamiya, E. J. Am. Chem. Soc. 2005, 127, 11892.

(27) Sgourakis, N. G.; Yan, Y.; McCallum, S. A.; Wang, C.; Garcia, A. E. J. Mol. Biol. 2007, 368, 1448.

(28) Atwood, C. S.; Huang, X.; Moir, R. D.; Tanzi, R. E.; Bush, A. I. Met. Ions Biol. Syst. 1999, 36, 309.

(29) Atwood, C. S.; Perry, G.; Zeng, H.; Kato, Y.; Jones, W. D.; Ling, K. Q.; Huang, X.; Moir, R. D.; Wang, D.; Sayre, L. M.; Smith, M. A.; Chen, S. G.; Bush, A. I. Biochemistry 2004, 43, 560.

(30) Huang, X.; Atwood, C. S.; Moir, R. D.; Hartshorn, M. A.; Tanzi, R. E.; Bush, A. I. J. Biol. Inorg. Chem. 2004, 9, 954.

(31) Kirschner, D. A.; Abraham, C.; Selkoe, D. J. Proc. Natl. Acad. Sci. U.S.A. 1986, 83, 503.

(32) Balbach, J. J.; Petkova, A. T.; Oyler, N. A.; Antzutkin, O. N.;

Gordon, D. J.; Meredith, S. C.; Tycko, R. Biophys. J. 2002, 83, 1205.

(33) Chauhan, V.; Chauhan, A. Pathophysiology 2006, 13, 195.

(34) Quist, A.; Doudevski, I.; Lin, H.; Azimova, R.; Ng, D.; Frangione, B.; Kagan, B.; Ghiso, J.; Lal, R. Proc. Natl. Acad. Sci. U.S.A. 2005, 102, 10427.

(35) Bush, A. I. Neurobiol. Aging 2002, 23, 1031.

(36) Lansbury, P. T. Jr. Curr. Opin. Chem. Biol. 1997, 1, 260.

(37) Doig, A. J. Curr. Opin. Drug Discovery Dev. 2007, 10, 533.

(38) Lazo, N. D.; Grant, M. A.; Condron, M. C.; Rigby, A. C.; Teplow, D. B. Protein Sci. 2005, 14, 1581.

(39) Petkova, A. T.; Yau, W. M.; Tycko, R. Biochemistry 2006, 45, 498. 004

(40) Buchete, N. V.; Tycko, R.; Hummer, G. J. Mol. Biol. 2005, 353,

(41) Petkova, A. T.; Leapman, R. D.; Guo, Z.; Yau, W. M.; Mattson, M. P.; Tycko, R. Science 2005, 307, 262.

(42) Gordon, D. J.; Meredith, S. C. Biochemistry 2003, 42, 475.

(43) Sciarretta, K. L.; Boire, A.; Gordon, D. J.; Meredith, S. C. Biochemistry 2006, 45, 9485.

(44) Scheibel, T.; Parthasarathy, R.; Sawicki, G.; Lin, X. M.; Jaeger, H.; Lindquist, S. L. Proc. Natl. Acad. Sci. U.S.A. 2003, 100, 4527.
(45) Baumketner, A.; Bernstein, S. L.; Wyttenbach, T.; Lazo, N. D.; Teplow, D. B.; Bowers, M. T.; Shea, J. E. Protein Sci. 2006, 15, 1239. (46) Wei, G.; Shea, J. E. Biophys. J. 2006, 91, 1638.

(47) Massi, F.; Peng, J. W.; Lee, J. P.; Straub, J. E. Biophys. J. 2001, 80,31 .

(48) Urbanc, B.; Cruz, L.; Ding, F.; Sammond, D.; Khare, S.; Buldyrev, S. V.; Stanley, H. E.; Dokholyan, N. V. Biophys. J. 2004, 87, 2310.

(49) Tarus, B.; Straub, J. E.; Thirumalai, D. J. Mol. Biol. 2005, 345, 1141

(50) Huet, A.; Derreumaux, P. Biophys. J. 2006, 91, 3829.

(51) Hwang, W.; Zhang, S.; Kamm, R. D.; Karplus, M. Proc. Natl. Acad. Sci. U.S.A. 2004, 101, 12916

(52) Gnanakaran, S.; Nussinov, R.; Garcia, A. E. J. Am. Chem. Soc. 2006, $128,2158$.

(53) Klimov, D. K.; Thirumalai, D. Structure 2003, 11, 295.

(54) Ma, B.; Nussinov, R. Biophys. J. 2006, 90, 3365

(55) Buchete, N. V.; Hummer, G. Biophys. J. 2007, 92, 3032

(56) Rohrig, U. F.; Laio, A.; Tantalo, N.; Parrinello, M.; Petronzio, R. Biophys. J. 2006, 91, 3217.

(57) Petkova, A. T.; Ishii, Y.; Balbach, J. J.; Antzutkin, O. N.; Leapman, R. D.; Delaglio, F.; Tycko, R. Proc. Natl. Acad. Sci. U.S.A. 2002, 99, 16742. (58) Paravastu, A. K.; Petkova, A. T.; Tycko, R. Biophys. J. 2006, 90 , 4618

(59) Berman, H. M.; Battistuz, T.; Bhat, T. N.; Bluhm, W. F.; Bourne, P. E.; Burkhardt, K.; Feng, Z.; Gilliland, G. L.; Iype, L.; Jain, S.; Fagan, P.; Marvin, J.; Padilla, D.; Ravichandran, V.; Schneider, B.; Thanki, N.; Weissig, H.; Westbrook, J. D.; Zardecki, C. Acta Crystallogr., Sect. D 2002, 58,899 .

(60) Berendsen, H. J. C.; Postma, J. P. M.; von Gunstaren, W. F.; Hermans, J. In Intermolecular Forces, Pullman, B., Ed.; Reidel: Dordrecht, Holland, 1981; p 331.

(61) Meersman, F.; Dobson, C. M. Biochim. Biophys. Acta 2006, 1764, 452.

(62) Sasahara, K.; Naiki, H.; Goto, Y. J. Mol. Biol. 2005, 352, 700.

(63) Van Der Spoel, D.; Lindahl, E.; Hess, B.; Groenhof, G.; Mark,

A. E.; Berendsen, H. J. J. Comput. Chem. 2005, 26, 1701.

(64) Kaminski, G. A.; Friesner, R. A.; Tirado-Rives, J.; Jorgensen, W. L.

J. Phys. Chem. B 2001, 105, 6474.

(65) Berendsen, H. J. C.; Postma, J. P. M.; van Gunsteren, W. F.; DiNola,

A.; Haak, J. R. J. Chem. Phys. 1984, 81, 3684.

(66) Hess, B.; Bekker, H.; Berendsen, H. J. C.; Fraaije, J. G. E. M.

J. Comput. Chem 1997, 18, 1463.

(67) Miyamoto, S.; Kollman, P. A. J. Comput. Chem. 1992, 13, 952.

(68) Darden, T.; York, D.; Pedersen, L. J. Chem. Phys. 1993, 98, 10089.

(69) Beke, T.; Csizmadia, I. G.; Perczel, A. J. Am. Chem. Soc. 2006,

128,5158 .

(70) Kabsch, W.; Sander, C. Biopolymers 1983, 22, 2577.

(71) Humphrey, W.; Dalke, A.; Schulten, K. J. Mol. Graphics 1996, 14,33 .

(72) Pettersen, E. F.; Goddard, T. D.; Huang, C. C.; Couch, G. S.; Greenblatt, D. M.; Meng, E. C.; Ferrin, T. E. J. Comput. Chem. 2004, 25, 1605.

(73) Massi, F.; Klimov, D.; Thirumalai, D.; Straub, J. E. Protein Sci. 2002, 11, 1639 .

(74) Kirkitadze, M. D.; Condron, M. M.; Teplow, D. B. J. Mol. Biol. 2001, 312, 1103

(75) Dima, R. I.; Thirumalai, D. Bioinformatics 2004, 20, 2345.

(76) Thirumalai, D.; Klimov, D. K.; Dima, R. I. Curr. Opin. Struct. Biol. 2003, 13, 146 .

(77) Borreguero, J. M.; Urbanc, B.; Lazo, N. D.; Buldyrev, S. V.; Teplow, D. B.; Stanley, H. E. Proc. Natl. Acad. Sci. U.S.A. 2005, 102, 6015.

(78) Cruz, L.; Urbanc, B.; Borreguero, J. M.; Lazo, N. D.; Teplow, D. B.; Stanley, H. E. Proc. Natl. Acad. Sci. U.S.A. 2005, 102, 18258.

(79) Ferguson, N.; Becker, J.; Tidow, H.; Tremmel, S.; Sharpe, T. D.; Krause, G.; Flinders, J.; Petrovich, M.; Berriman, J.; Oschkinat, H.; Fersht, A. R. Proc. Natl. Acad. Sci. U.S.A. 2006, 103, 16248.

(80) Zheng, J.; Ma, B.; Nussinov, R. Phys. Biol. 2006, 3, P1.

(81) Esposito, L.; Pedone, C.; Vitagliano, L. Proc. Natl. Acad. Sci. U.S.A. 2006, 103,11533

(82) Zheng, J.; Ma, B.; Tsai, C. J.; Nussinov, R. Biophys. J. 2006, 91, 824.

(83) Chothia, C.; Janin, J. Biochemistry 1982, 21, 3955

(84) Periole, X.; Rampioni, A.; Vendruscolo, M.; Mark, A. E. J. Phys. Chem. B 2009, 113, 1728 .

(85) Ma, B.; Nussinov, R. Proc. Natl. Acad. Sci. U.S.A. 2002, 99, 14126.

(86) Williams, A. D.; Portelius, E.; Kheterpal, I.; Guo, J. T.; Cook, K. D.;

Xu, Y.; Wetzel, R. J. Mol. Biol. 2004, 335, 833.

(87) Shivaprasad, S.; Wetzel, R. Biochemistry 2004, 43, 15310.

JP901057W 